\title{
Elastic protection coatings for ship fuel tanks, intended for the increasing of environment protection level
}

\author{
Janusz Kozak \\ Gdansk University of Technology
}

\begin{abstract}
Small closed sea shipping regions (such as the Baltic Sea) are specially vulnerable to consequences of ecological disasters due to spills of fuel oil used for ship propulsion and carried in single-plating double-bottom tanks. An alternative solution (against the recommended double-plating structure) was proposed. It consists in applying the second, elastic protection barrier to decrease risk of oil spills resulting from loss of tightness of ship plating in consequence of e.g. collision or grounding.
\end{abstract}

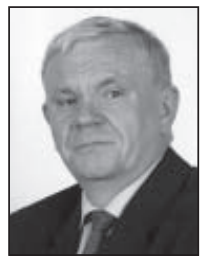

Keywords : elastic protection coatings, ship tanks, environment protection

\section{INTRODUCTION}

Dramatic increase of amount of cargo shipped by sea and associated increase of number of cargo ships, observed in the world fleet for several last years, has been mainly caused by progressing process of economy globalization. For this reason many sea regions of the world have become more busy and hazardous for navigation. Small closed navigation regions are specially endangered by possible sea disasters. One of them is the Baltic Sea [1]. On average about 2000 ships every day sail in this waters, Fig. 1.

These are ships of different types; out of the total number of 13600 ships crossing Skagen between July 2005 and October $2005,60 \%$ of them belonged to dry cargo ships, $25 \%$ - tankers, $7 \%$ - passenger ships and 8\% - other ships [2]. Main shipping routes in the Baltic are presented in Fig. 2.

Moreover, a further dynamic increase of number of cargo ships sailing in the Baltic waters is predicted - Fig. 3 [2].

The Baltic Sea basin is a specific region of the world not only due to the busy shipping routes. It is a sea of a very limited amount of water exchanged with the ocean - the time necessary to completely exchange its water with the Atlantic Ocean is estimated to be $25 \div 30$ years, which means that in the case of a greater oil spill in the region its consequences will be severe and long-lasting. According to the performed analyses [3] the probable profit loss resulting from tourism limitation in a spill suffering region would be many times greater than pollution removal cost. Additionally, in the Baltic waters - apart from shipping routes - in coastal zones are also carried out other activities such as fishing, tourism and operation of farms of wind power plants.

The very intensive ship traffic over the restricted area of the Baltic greatly influences occurrence number of sea accidents.

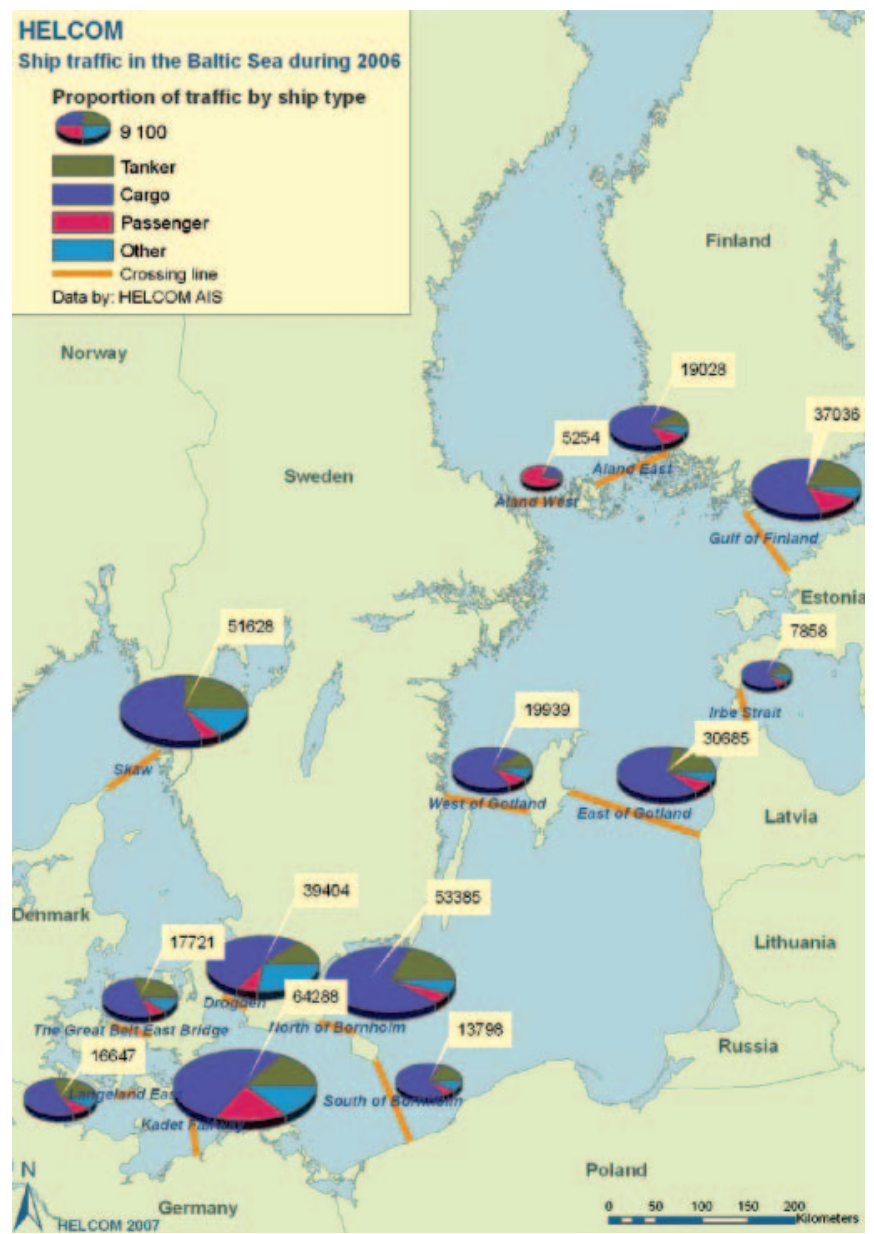

Fig. 1. Ship traffic in the Baltic Sea [2] 


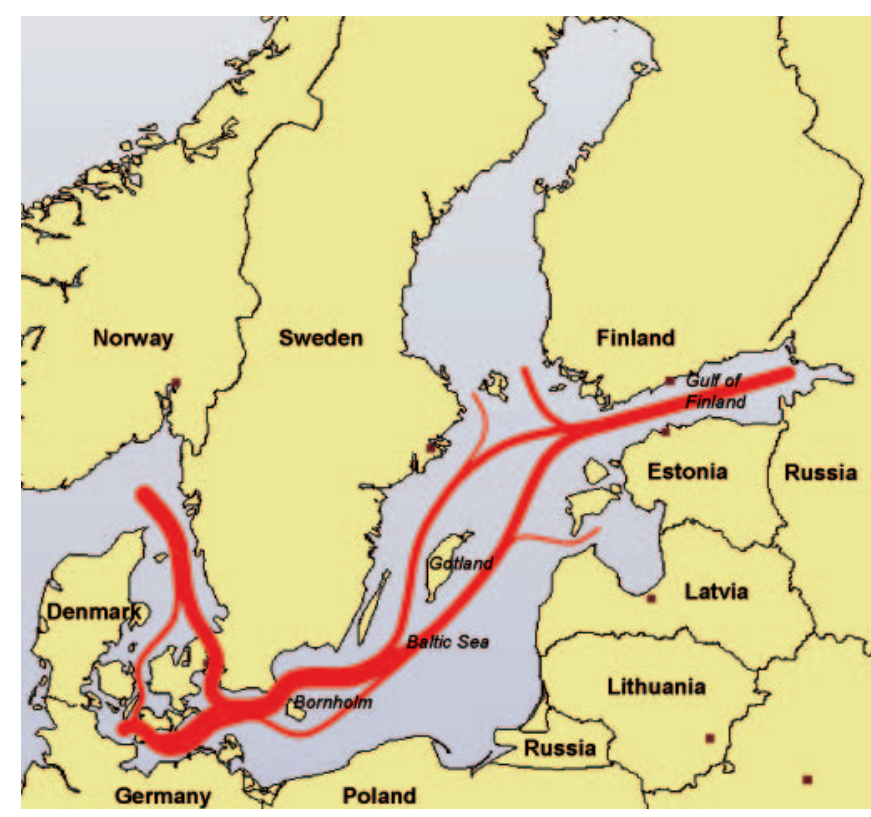

Fig. 2. Main shipping routes in the Baltic Sea [3]

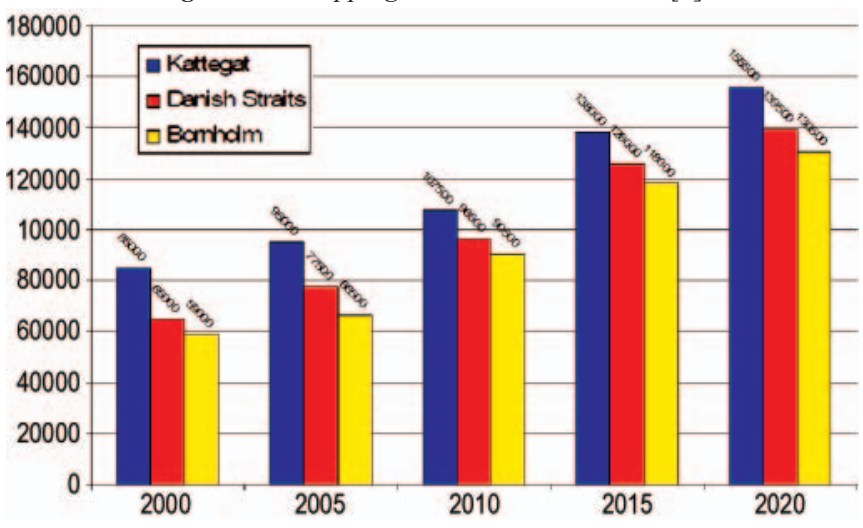

Fig. 3. Ship traffic intensity (ships/year) in the Baltic [4]

The high traffic intensity, difficulty in navigation through the straits leading from the North Sea to the Baltic, often occurring bad weather conditions and other factors make that the Baltic is a sea region where many ship accidents occur year by year. The highest number of 146 sea accidents was recorded in 2005; as many as 13 of which resulted in pollution of the environment [4].

The map of particular kinds of the accidents together with indication of places of their occurrence is presented in Fig. 4.

In the years 2000-2006 the most frequent cause of ship accidents was grounding (46\%), the next one - ship-to-ship collisions $(31 \%)$. A failure of ship power plant or structure was responsible for disasters in 3\% cases, and fire - in 5\%. The most severe accidents which caused oil spills in the Baltic are listed in Tab. 1.

Tab. 1. The most severe pollutions caused by spills of oil product materials from ships in the Baltic waters [6]

\begin{tabular}{|c|c|c|c|}
\hline Year & Ship name & $\begin{array}{c}\text { Amount of } \\
\text { spilled oil }\end{array}$ & Place \\
\hline $\mathbf{2 0 0 3}$ & Fu Shan Hai & $1200 \mathrm{t}$ & $\begin{array}{c}\text { Bornholm } \\
\text { (Denmark/Sweden) }\end{array}$ \\
\hline $\mathbf{2 0 0 1}$ & Baltic Carrier & $2700 \mathrm{t}$ & $\begin{array}{c}\text { Kadetrenden } \\
\text { (Denmark) }\end{array}$ \\
\hline $\mathbf{1 9 9 8}$ & Nunki & $100 \mathrm{~m}^{3}$ & $\begin{array}{c}\text { Fjord Kalundborg } \\
\text { (Denmark) }\end{array}$ \\
\hline $\mathbf{1 9 9 5}$ & Hual Trooper & $180 \mathrm{t}$ & $\begin{array}{c}\text { Sund (Sweden) } \\
\text { Karlskrona } \\
\text { (Sweden) }\end{array}$ \\
\hline $\mathbf{1 9 9 0}$ & Volgoneft & $1000 \mathrm{t}$ & \multicolumn{2}{c}{} \\
\hline
\end{tabular}

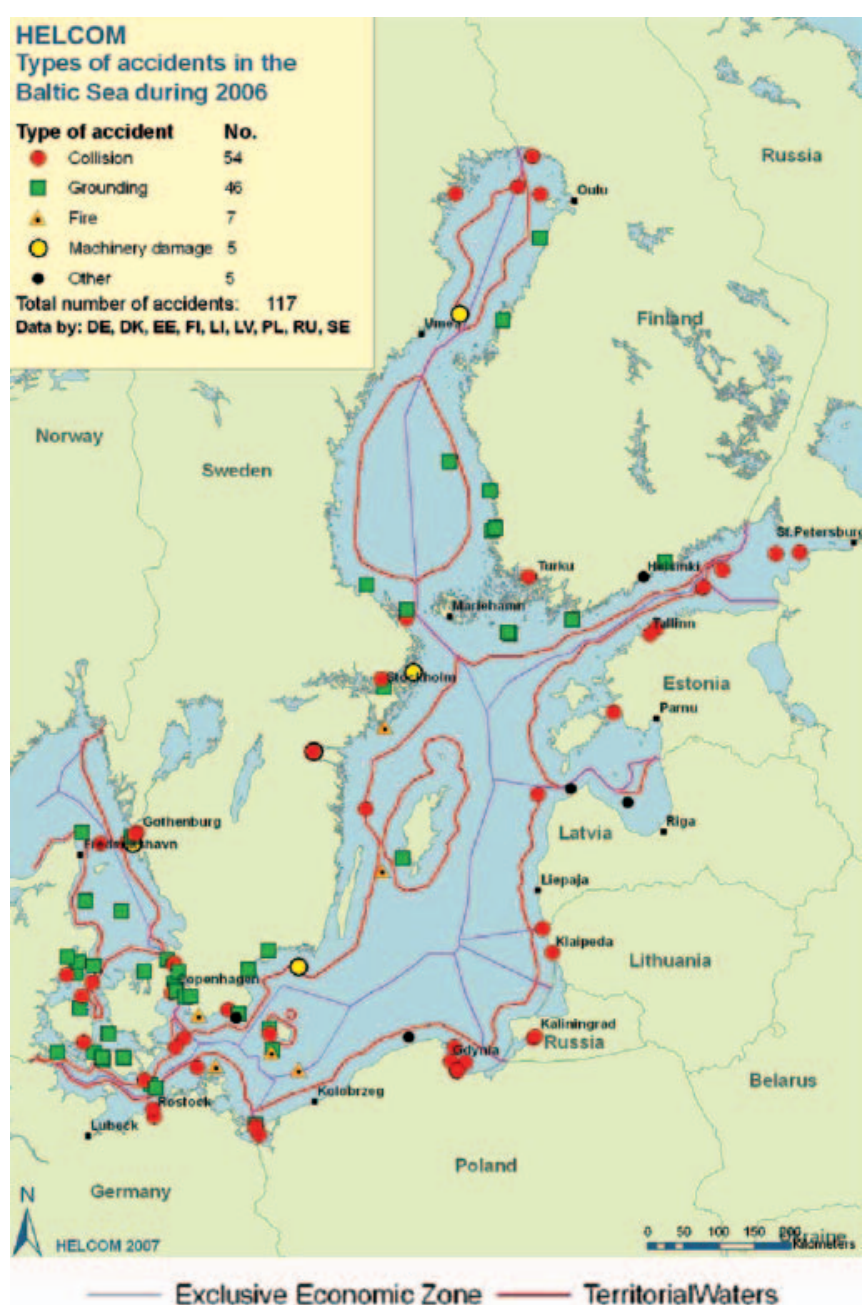

Fig. 4. Places where ship accidents occurred at the Baltic Sea in 2006 [5]

In the connection with the increasing risk of ecological disasters associated with sea transport, in the last years the European Union adopted two packages of legal instruments dealing with safety at sea, the so called principles: Erika I and Erika II. As a result of their implementation the range of port control of ships was intensified and extended, and single side plating ships were banned from oil shipping; also, the European Maritime Safety Agency (EMSA) was established. In 2005 the European Commission prepared the package Erika III.

In the existing and being- in- force requirements for construction and equipment of new ships possible collisions and groundings have not been taken into account. Only basic design regulations concerning stability and floatability of damaged ships or amount of spill of liquid load from damaged hull are commonly adopted. However in 2004 Germanischer Lloyd (GL) introduced to its rules the notation COLL which determines degree of ship hull resistance (strength) against collisions [7]. The resistance is measured by comparing the strength against impact of strengthened ship side structure with that not strengthened of single plating. The only regulations directly concerning collisions are the requirements for ships intended for inland navigation on the Rhine (Switzerland, Germany, the Netherlands), introduced in 2003. The ADNR regulations require to so design structural elements of gas tankers as to make them able to absorb the energy of $22 \mathrm{MJ}$ released during collision against ship side structure [8].

Though for cargo tanks of oil cargo tankers the legal requirements have been recently made much more stringent, 
similar ones for fuel oil tanks are still lacking, nevertheless amount of fuel oil contained in them is often comparable with that of liquid cargo carried by a small tanker. The hazard becomes greater by the fact that most of such tanks is located in double bottom, i.e. in the zone very susceptible to failure both in the case of ship-to-ship collision and the taking of ground or rock.

\section{IDEA OF THE PROGRAMME CORET}

The above mentioned premises indicate that grounding or collision of e.g. a container carrier of medium size may lead to environmental pollution of the Baltic by the oil released from unseal single plating bottom tanks and its amount can be significant. In this connection was undertaken a research work aimed at elaboration of a way of lowering the risk of releasing oil spill in the case of collision, by introducing a second protection barrier. The idea of the project consists in adding an internal elastic oil-resisting coating placed inside the tank on a foundation which fills the tank in such a way as to ensure - in the case of tank plating tear occurring as a result of a collision - tightness of the tank by means of the elastic coating able to be displaced to some distance and thus to prevent against oil spill in emergency, Fig. 5.

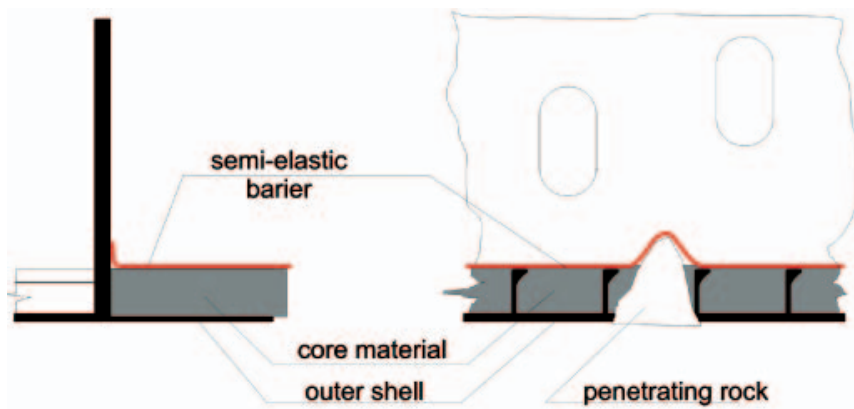

Fig. 5. Idea of the second elastic barrier for fuel oil bottom tank.

In order to elaborate such novel solution many problems should be first investigated including the following:

$\Rightarrow$ elaboration of recipe for an oil resistant plastic material, inexpensive and suitable for coating it inside closed spaces in shipyard's conditions.

$\Rightarrow$ selection of a material for intermediate filling layer,

$\Rightarrow$ elaboration of an engineering process of applying the components of the barrier in industrial conditions with special taking into account difficult places such as corners, bends etc,

$\Rightarrow$ selection of the dimensions of the second barrier components: depth of the filling layer and thickness of the protection coating,

$\Rightarrow$ influence of the additional coating and filling material on corrosion rate of steel structure,

$\Rightarrow$ elaboration of a method for control of state of hidden surfaces,

$\Rightarrow$ making agreement with classification societies as to principles of implementation and use of the novel solution.

The mentioned problems constitute the subject of work carried out in the frame of the research project EUREKA E!3614 „CORET”: “Elastic protection coatings for ship tanks to increase environment protection level ". Below are presented results of a preliminary work associated with developing some of the above mentioned problems.

\section{SELECTION OF A FILLING MATERIAL INTENDED FOR SUPPORTING THE SECOND BARRIER}

During searching for a filling material for supporting the elastic internal barrier, was performed a comprehensive research study to select materials which satisfy majority of a dozen or so requirements, often contradictory to each other. Such filling material should be light in weight, non-flammable, non-gassing in an elevated temperature, non-toxic, noncorrosive, easy for implementing in industrial conditions, easily utilized and inexpensive, of course. After reviewing possibly applicable materials it was revealed that lightweight concretes can fulfill most of the postulated features. The concretes are of the volumetric density not greater than $2000 \mathrm{~kg} / \mathrm{m}^{3}$ in dry state. In land structures they are used to significantly lower weight of an element and/or its dimensions. The concretes are made by mixing cement mortar and various natural or artificial aggregates. Application of lightweight aggregates makes it possible to obtain the concretes of the strength exceeding $60 \mathrm{MPa}$, at simultaneous reduction of structural weight by $25 \div 30 \%$ relative to the common concrete. It leads to a significant reduction of cost of shuttering, scaffolding and reinforcement, as well as to a reduction of dimensions of structural elements, thus - total volume of concrete, and to reaching a greater freedom of designing. The application of lightweight artificial aggregates to concretes results not only from the need of obtaining more lightweight structures but also from limited resources of rock aggregates and economic necessity of utilization of industrial wastes. This is especially important in the aspect of implementing the balanced development policy recommended by European Union.

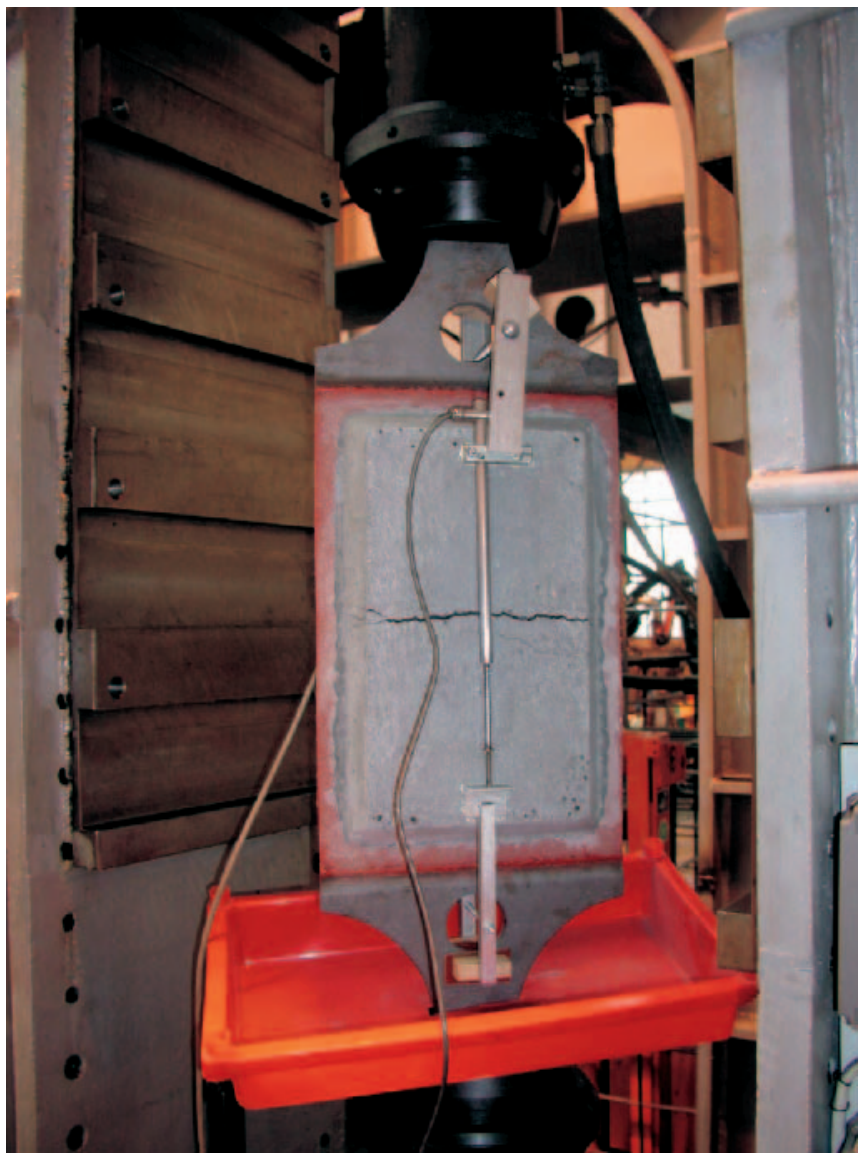

Fig. 6. Tests of mechanical properties of filling layer 
A characteristic common feature of all lightweight aggregates is their porous structure and - as a rule - a lower strength than that of hardened cement mortar. Consequently, concretes made of the aggregates differ from common ones not only in their volumetric density but also other features as well as manufacturing process.

During the work on choice of parameters of concrete filling material, the laboratory tests of mechanical properties of various combinations of concrete and aggregate, and on applicable way of preparation of steel structure surface, were carried out by using full-scale specimens. In Fig. 6 is presented the specimen tested to determine a degree of binding the filling material with the steel structure under tension, depending on a way of preparation of steel plate surface, and in Fig. 7 - the example record of deformation of the concrete filling material versus deformation of the steel structure.

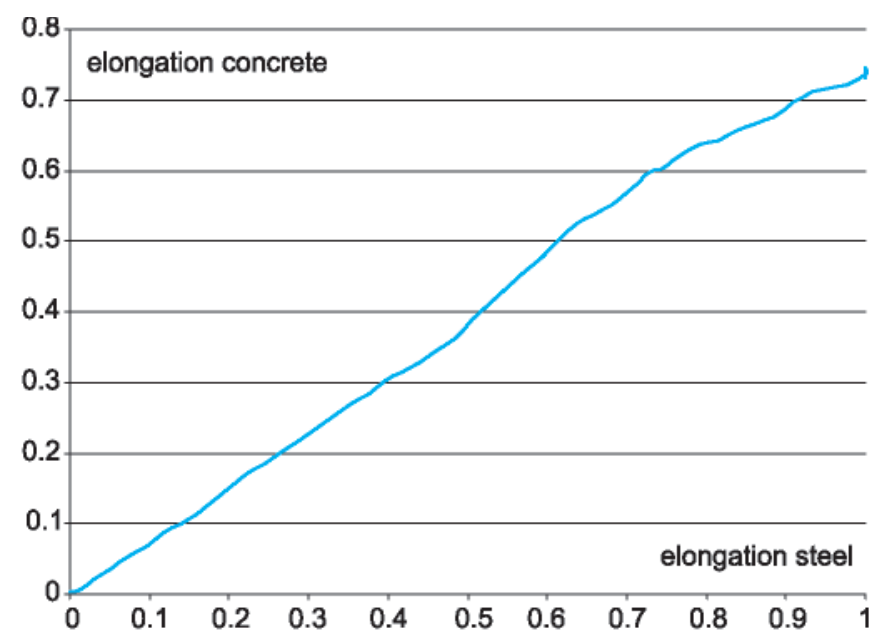

Fig. 7. Relative elongation of concrete filling material versus elongation of deforming steel structure.

\section{SELECTION OF AN INTERMEDIATE LAYER BETWEEN THE CONCRETE FILLER AND 2ND BARRIER COATING}

Concrete - especially lightweight one - is, after applying, a porous, fragile material which contains significant amount of water for a long time after forming. From the properties result problems of weak adhesion to smooth steel background, as well as of worsening the features of the $2^{\text {nd }}$ barrier layer applied ,in situ" because - as a result of the water released from the concrete - water vapour bubbles able to lower mechanical properties and tightness of applied layer of the $2^{\text {nd }}$ protection barrier, appear. Therefore one of the tasks of the carried out project was devoted to the finding of solutions for the increasing of lightweight concrete adhesion to steel background as well as to the $2^{\text {nd }}$ barrier layer so as to stop releasing the water contained in concrete, during application process of the $2^{\text {nd }}$ barrier. The mentioned problems were solved by introducing an intermediate layer combined of epoxide resins and quartz sand [9]. Effectiveness of the solutions was checked by means of strength tests of the obtained concrete-coating connection by applying both the tensile test pieces - such as shown in Fig. 6, and the test of pull-off the coating from the background - in the way as in the case of paint coatings, Fig. 8.

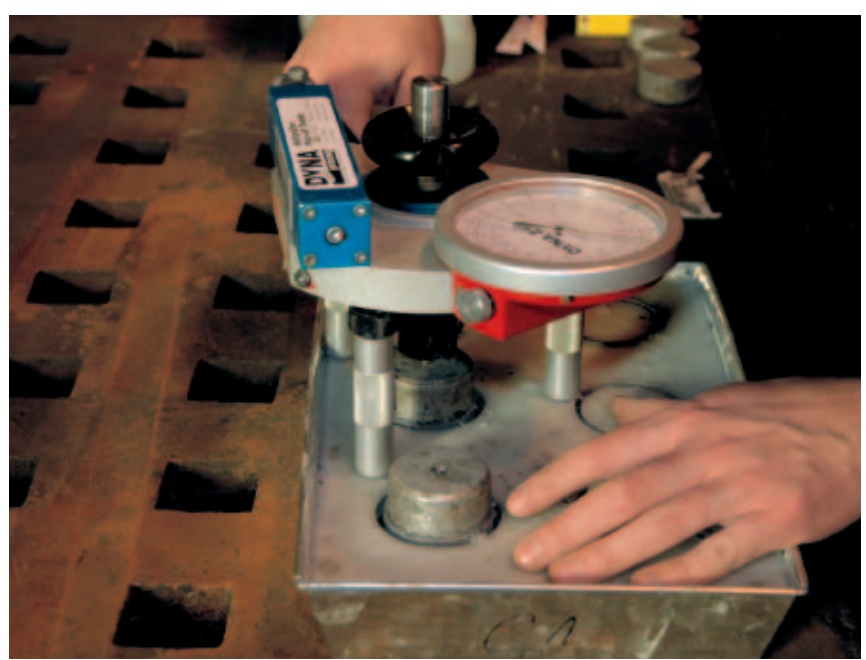

Fig. 8. Measurements of adhesion of concrete filler to protective barrier

\section{SUMMARY}

Large number of cargo ships sailing over small, restricted water areas such as the Baltic Sea can endanger - in the case of disaster -the environment by spilling fuel oil carried in the ship's bottom tanks for ship propulsion.

An alternative solution (against the double plating structure) was proposed consisting in applying the second, elastic protection barrier to decrease risk of oil spill resulting from loss of tightness of ship plating as a consequence of e.g. collision or grounding.

Implementation of such solution would make it possible to increase safety of existing ships without necessity of their expensive rebuilding.

\section{BIBLIOGRAPHY}

1. Maritime Transport in the Baltic Sea. Draft HELCOM Thematic Assessment in 2006. HELCOM Stakeholder Conference on the Baltic Sea Action Plan 07.03.2006, Helsinki, Finland

2. Baltic Master: General Assumptions Of The Ship Safety On Southern And Western Baltic Sea, Report (M II part 2/4), Maritime University of Szczecin, 2006

3. SSPA Sweden AB : Socioekonomiska Effekter Av Större Oljepåslag - Scenariostudier För Halland, Skåne, Blekinge Och Kalmar Län, Rapport till Räddningsverket, September 2006

4. Report on ship's accidents in the Baltic Sea area for the year 2004. Issued by HELCOM 2004

5. Report on shipping accidents in the Baltic Sea area for the year 2006, HELSINKI COMMISSION, August 2007

6. Baltic Master : Statistics on accidents and sea traffic, August 2006

7. Germanischer Lloyd : Strengthening against Collisions, Rules for Classification and Construction, Ship Technology Part 1 - Seagoing Ships, Chapter 1 - Hull Structures, Section 33, Germanischer Lloyd, Hamburg 1992

8. Rules for the Transport of Dangerous Cargo on the Rhine (in German, French and Dutch), http://www.ccr-zkr.org, ADNR 2003

9. Jeżewski M., Krasowski C. : Lightweight aggregate concrete - its composition and basic properties (in Polish), Raport 2007, WOiO/E/C/14/07 Gdansk, Poland 